九州大学学術情報リポジトリ

Kyushu University Institutional Repository

Relationship Between Forest Stand Density, Leaf Surface Area, and Amount of Photosynthesis and Transpiration in the Coastal Black Pine Forest of Northern Kyushu

Kim, Young-Jin

Graduate School of Social and Cultural Studies, Kyushu University

Yahata, Hisashi

Emeritus Professor of Kyushu University

Kurosawa, Kiyoshi

Institute of Tropical Agriculture, Kyushu University

Park, Seok-Gon

Graduate School of Social and Cultural Studies, Kyushu University

https://doi.org/10.5109/16113

出版情報: 九州大学大学院農学研究院紀要. 54 (2)，pp.347-352，2009-10-29. Faculty of Agriculture, Kyushu University

バージョン：

権利関係 : 


\title{
Relationship Between Forest Stand Density, Leaf Surface Area, and Amount of Photosynthesis and Transpiration in the Coastal Black Pine Forest of Northern Kyushu
}

\author{
Young-Jin KIM ${ }^{1 *}$, Hisashi YAHATA ${ }^{2}$, Kiyoshi KUROSAWA ${ }^{3}$ \\ and Seok-Gon PARK ${ }^{1}$ \\ Institute of Tropical Agriculture, Kyushu University, Hakozaki, \\ Fukuoka 812-8581, Japan \\ (Received June 30, 2009 and accepted July 13, 2009)
}

\begin{abstract}
The leaf surface area, biomass of leaves, and amount of photosynthesis and transpiration of trees for the unit forest area were measured over the course of a year in the coastal black pine forests of various stand densities in Northern Kyushu. The hydraulic resistance, i.e., the ratio of water potential to transpiration rate, at the top and middle of long branches was also measured in summer, when the rate was high. As a result, as the forest stand density became lower, the leaf surface area, biomass of leaves, and photosynthesis amount increased. The amount of transpiration amount positively correlated with the amount of photosynthesis. There was no difference in hydraulic resistance between the top and middle of the branches, demonstrating that the ability of growth was maintained even at the ends of the branches. Here, further branch growth could be expected. With the lowering of the forest stand density by thinning the number of trees, forest stand growth will be promoted by the action of photosynthesis and the expected growth of branches.
\end{abstract}

Keywords: stand density, hydraulic resistance, branch, tree growth

\section{INTRODUCTION}

The forest located in the coastal area, which is usually composed of black pines (Pinus thunbergii), protects the residential and agricultural lands behind the forest from strong wind, blowing sand and salt, etc., but the forest is not always well managed. There are many un-thinned forests, which have slim trunk size compared to tree height (Kaneko and Tamura, 2002). The desired structure of the forest to prevent disasters in the coastal area is one with a large crown size, and branch height that is low, resulting in large crown biomasses (Osada, 2004).

As for a forest having a larger branch biomass, the photosynthesis rate was larger and so was the transpiration rate (Kosugi et al., 1997). However, photosynthesis and transpiration rates were influenced by both light and air temperature conditions, resulting in variances due to time (Kikuzawa and Lechosics, 2006; Zots and Winter, 1994, 1996; Zots et al., 1995). There have been few studies on biomass growth based on the effect of photosynthesis and transpiration for tree leaves except by Holbrook and Lund (1995), who studied these effects on the Chalate species of tree (Ficus insipid).

In fact, there are no studies in black pine forests on the relationship between the biomass of leaves and the effect of photosynthesis and transpiration.

In the present study, the authors measured leaf surface area, photosynthesis, and transpiration amounts for a year on the coastal black pine forests located in Fukuoka

\footnotetext{
Graduate School of Social and Cultural Studies, Kyushu University, 819-0395, Fukuoka, Japan

Emeritus Professor of Kyushu University, 812-8581, Fukuoka, Japan

Institute of Tropical Agriculture, Kyushu University, 812-8581, Fukuoka, Japa

* Corresponding author (E-male: youngflh88@hotmail.com)
}

city. The authors also measured the hydraulic resistance, expressed by the ratio of water potential to transpiration rate, which is an indicator of the growth ability (Nagasuga and Kubota, 2006), at the top and middle of branches having different lengths.

From the measurements, the present study aimed to clarify the following: how the leaf surface area and biomass of leaves relate to the forest stand density; how the photosynthesis and transpiration amounts are affected by the leaf surface area and biomass of leaves; whether the hydraulic resistance changes between the top and middle of the branch or not, and with branch length; and, how the forest growth is affected with these results if the forest is thinned.

\section{MATERALS AND METHODS}

\section{Outline of the study area}

The study area is located in the coastal area of Fukuoka City in Northern Kyushu as shown in Fig. 1. The study area is divided into two zones, the Sawara and the Uminonakamichi.

The Sawara is located on a sand dune. The sand dune has a width of $30 \mathrm{~m}$. Little grass grows on the surface of the sand due to windstorms. The forest, having been a windbreak forest and a national park since 1956, has 20 ha in area with $3 \mathrm{~km}$ along the coastline. A portion of the forest is part of the Kyushu University Forest. The area behind the forest is a residential area. In this study, S1 and S2 stands (Fig. 1), where the black pines were planted in 1991 and 1996, were targeted. For S2 stand, black pines were planted at the year at a low density immediately after the forest fire.

The Uminonakamichi zone is located on a sand bar and is a part of a national park with 540 ha in area. The sand bar connects the Shikanoshima Island with Fukuoka 


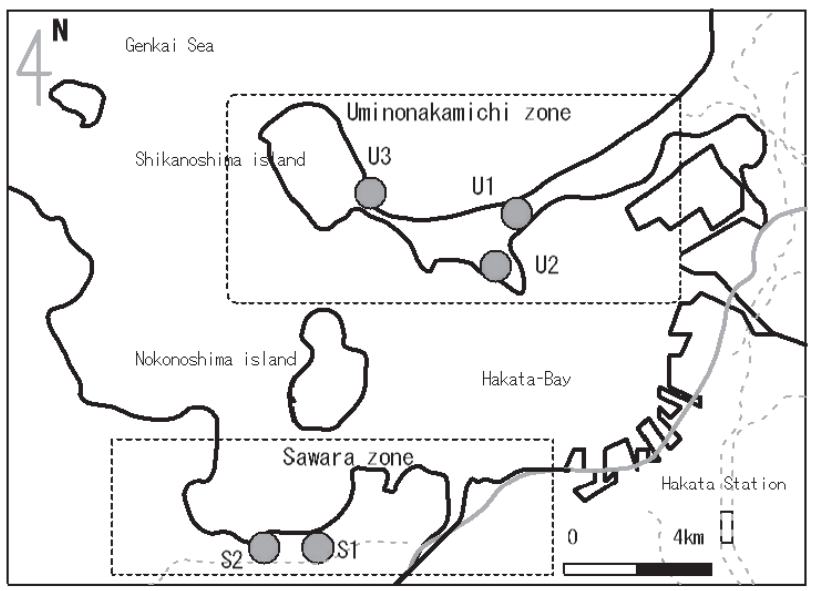

Fig. 1. Location of the study area.

City's mainland. There the forest that has 143 ha of area composed of black pines. Here, 3 forest stands of U1, U2 and U3 (Fig. 1), where the trees were planted in 1989, were targeted.

Each forest stand, S1, S2, U1, U2, and U3 has an area of $100 \mathrm{~m}^{2}$. The forests in the two zones have not been managed well, and there are some decaying branches on the trees in the forest.

According to Japan Meteorological Agency (2009), the study area is located in a zone, where the annual mean value of precipitation, air temperature, sunshine hours, and wind speed is $1,400-1,800 \mathrm{~mm}, 15-18^{\circ} \mathrm{C}$, 1,700-1,900 hours, and $2-4 \mathrm{~m} / \mathrm{s}$, respectively.

The elevation above sea level is $1-3 m$ in these zones. The waves on the sea around the study area are relatively calm, and the sand particles are easily deposited along the coastline. The geology consists of alluvial materials.

\section{Measurement of forest stand condition}

In each stand, a plot of $10 \mathrm{~m}$ by $10 \mathrm{~m}$ in area was selected, and the number of trees growing there was counted, and the diameter of the breast height and the tree height were measured for each tree. In addition, the length and width of the crown were measured by survey taping and the height measuring gauge for each tree. These measurements were averaged for the plot. The measurements were done for 3 plots differentially located in the stand and the total average was calculated.

\section{Measurement of the leaf surface area}

A total of 10 branches were sampled from 10 respective trees in each forest, and the number of leaves growing on the $10 \mathrm{~cm}$ long section of the current, $1^{\text {st }}$, and $2^{\text {nd }}$ year shoots of the branch were counted. A schematic diagram showing each year's shoots is shown in Fig. 2. In Fig. 2, the first order branch is the branch growing directly from the trunk. The second and third order branches were grown from the first and second order branches, respectively. The shoot from the current year grows in front of the previous year's shoot. There is usually more than 1 shoot growing in the current year. The average is between $4 \& 5$ shoots. The longest shoot among these is known as the main shoot. Leaves grow-

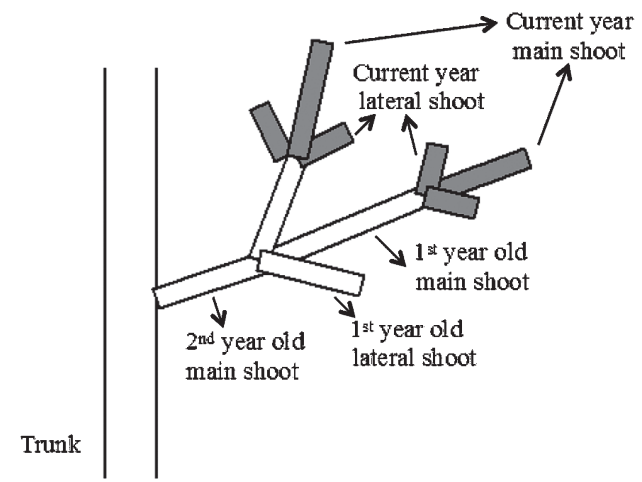

Branches are aggregate of the shoot of each year Each shoot consists of stem and leaves parts

Fig. 2. Schematic diagram of the shoot growth of a tree.

ing on a shoot can be seen in the current $1^{\text {st }}$ and $3^{\text {rd }}$ year shoots only. Leaves on shoots in other years have decayed with time.

The number of leaves growing on each shoot was derived by the number of leaves counted on a $10-\mathrm{cm}$ section of the shoot multiplied by the length of the shoot. The total number of leaves on the branch was derived by adding the number of leaves on every shoot.

Several leaves were sampled from the current $1^{\text {st }}$ and $2^{\text {nd }}$ year shoots, respectively, for the representative branch. A cross-sectional specimen of $0.3 \mu \mathrm{m}$ thick was taken by cutting from each leaf, and the length of the circumference was measured under a microscope. The length of the circumference was then averaged for several leaves. The surface area of each leaf was derived by the circumference length multiplied by the leaf length. For every leaf, its top $2 \mathrm{~cm}$ was angular, thus the surface area was calculated as a lateral area of a cone.

The surface area of a leaf multiplied by the number of leaves on each shoot gives the general leaf surface area of each shoot. Total leaf surface area of a branch was derived by summing the leaf surface area of every shoot, and total leaf surface area of a tree was derived by the leaf surface area of a branch multiplied by the number of branches for a tree. The total leaf surface area for a stand was derived by the leaf surface area of a tree multiplied by the number of trees on a stand.

For measuring the dry weight of leaves, 1,000 leaves were sampled from current, $1^{\text {st }}$ and $2^{\text {nd }}$ year shoots for 10 branches from their respective 10 trees for a stand. Those leaves were oven-dried, and their weight was counted. The number of leaves for a tree multiplied by the dry weight of single leaf (1/1,000 weight of 1,000 leaves) gave the biomass of leaves for a tree, and the biomass of leaves for a tree multiplied by the number of trees on a forest stand gave the biomass of leaves on the stand, respectively.

\section{Measurement of the photosynthesis rate of a tree and determination of the relationship between photosynthesis rate and PPFD}

The rate of photosynthesis for a tree was measured on several clear and still days by using a portable photo- 
synthesis system (LI6400, Li-Cor Inc.) in every month. Three representative trees were targeted in each stand. Five leaves on the tree were pinched with a device as part of the system. The photosynthesis rate was measured at two spots of the crown, where the light was different from each other. The condition of the light in one instance was a dark spot of $50-80 \%$ relative light intensity or 300-1,500 $\mathrm{\mu mol} \mathrm{m}^{-2} \mathrm{~s}^{-1}$ in PPFD (photosynthetic photon flux density) and the other type of condition was a welllighted spot of 30-50\% relative light intensity or 0-300 $\mathrm{\mu mol} \mathrm{m}^{-2} \mathrm{~s}^{-1}$ in PPFD. The rate of photosynthesis was measured hourly from sunrise to sunset with 3 replications. From these values of two spots and readings from several days of the month, the average daily transpiration amounts in each month could be derived.

On the other hand, daily PPFD values were calculated by using daily solar radiation over the whole sky observed at Fukuoka City during 2007 (Japan Meteorological Agency, 2009). PPFD was given by solar radiation over the whole sky multiplied by a constant of 2.3 as explained by Koike (2004).

Following this, the relationship between PPFD and the photosynthesis amount in a unit leaf surface area was determined. For photosynthesis, the amount usually depends on the season; therefore, the relationship was determined according to the season as shown in Fig. 3, and the daily photosynthesis amount during a year for a unit leaf surface area was calculated by using daily PPFD based on the relationship of Fig. 3 .

From the daily photosynthesis amount, the total annual amount of photosynthesis for the unit leaf surface area was calculated. The amount multiplied by the leaf surface area of a stand gave the annual total amount of photosynthesis.

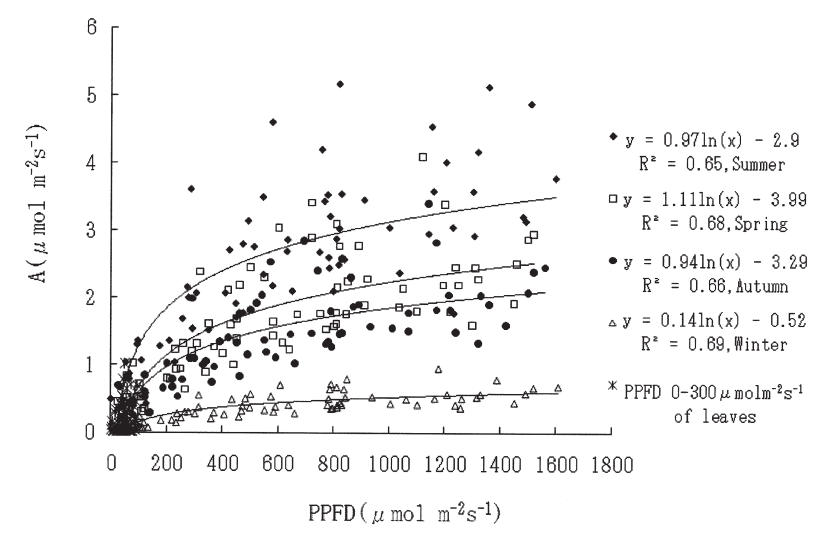

Fig. 3. Relationship between PPFD and photosynthesis rate (A: photosynthesis rate).

\section{Measurement of transpiration amount of a tree}

A tree, having an average height and diameter at breast height, was targeted for the measurement. A pair of transpiration sensors equipped with both a heating device and a reference sensor was placed on a tree $1 \mathrm{~m}$ below the breast high. A thermal coupling was set on top of these sensors to measure the difference in the sap temperature between the sensors. At this height, these paired sensors were inserted into the sapwood inside the trunk from 3 directions at an angle of 120 degrees. The Granier method, as introduced in Kumagai (2001) was used to measure sap flow velocity from the difference in the temperature of the sensors. The measurement was done once a month in 2007.

Cross sectional area of the sapwood was assumed from the sampling of the partial cross-section of a trunk by the increment borer.

Sap flow velocity multiplied by the cross sectional area of the sapwood gave the sap flow volume. By adding the hourly measured sap flow volume together, a total daily sap flow volume of a tree could be derived. This measurement was done for several days monthly during the year, and a monthly daily average was derived.

After that, the daily average sap flow volume was totaled for the year to obtain the total annual value. The total annual sap flow volume for a tree multiplied by the number of trees for a stand gave the total annual sap flow volume for the stand. This sap flow volume is equivalent to the total annual transpiration amount of a forest stand.

\section{Measurement of the hydraulic resistance of a branch}

The hydraulic resistance was measured for a branch, which has a long length and is grown to the medium height of the crown. A tree growing on the edge of the U1 stand and the neighboring wide-open area was targeted. The branches measured were 3 branches $4.3-6.5 \mathrm{~m}$ long for 3 respective trees. These branches extended from the trunk to the open space.

Compared to the crown width of $2.5 \mathrm{~m}$ of an average U1 stand (i.e. branch length was equivalent to $1.25 \mathrm{~m}$ ), the branch measured was fairly long. Here, the maximal maintenance of the growth ability of the branch was aimed at being clarified by the long branch.

For the branch, transpiration rate and water potential were measured hourly at the top and in the middle from 6 am to $6 \mathrm{pm}$. The measurement took place for 3 days continuously in August of 2007. The measurement of the transpiration rate was done by a super porometer (LI-1600, Li-Cor Inc.), and the water potential measurement was conducted by a method using a pressure chamber (Koike, 2004). Hydraulic resistance was given by the ratio of water potential to the transpiration rate.

\section{RESULTS}

\section{Condition of the forest stand}

Condition of each forest stand is summarized in Table 1. In $\mathrm{S} 1$, stand density was as low as 12 trees $/ 100 \mathrm{~m}^{2}$, stand age was also as low as 12 years, and tree height was $5.7 \mathrm{~m}$. The average crown length, crown width, diameter at the breast height, crown length ratio, and biomass of leaves were larger than the other stands. S2 stand had a high stand density of 59 trees $/ 100 \mathrm{~m}^{2}$, average crown length $(1.5 \mathrm{~m})$, crown width $(1.4 \mathrm{~m})$, diameter at breast height $(6.3 \mathrm{~cm})$, crown length ratio $(0.19)$, biomass of leaves $\left(0.07 \mathrm{t} / 100 \mathrm{~m}^{2}\right)$, which were the lowest among 
Table 1. Forest stand density, average values of crown length, crown width, tree height, diameter at breast height, tree age, crown length ratio, sapwood area of a trunk, biomass of leaves, and leaf surface area for each stand, and the amount of photosynthesis and transpiration for the stand

\begin{tabular}{lccccc}
\hline \multicolumn{1}{c}{ Forest stand } & S1 & S2 & U1 & U2 & U3 \\
\hline Stand density $\left(\right.$ trees $\left./ 100 \mathrm{~m}^{2}\right)$ & 12 & 59 & 15 & 20 & 29 \\
Crown length $(\mathrm{m})$ & 3.1 & 1.5 & 2.7 & 2.1 & 1.9 \\
Crown width $(\mathrm{m})$ & 3.2 & 1.4 & 2.5 & 1.9 & 1.7 \\
Tree height $(\mathrm{m})$ & 5.7 & 8.1 & 8.6 & 8.4 & 8.3 \\
Diameter at breast height $(\mathrm{cm})$ & 12.1 & 6.3 & 11.9 & 10.3 & 8.9 \\
Tree age (year) & 12 & 17 & 20 & 20 & 18 \\
Crown length ratio & 0.54 & 0.19 & 0.31 & 0.25 & 0.23 \\
Sapwood area of a trunk $\left(\mathrm{cm}^{2}\right)$ & 184 & 49 & 158 & 113 & 80 \\
Leaf surface area of one tree $\left(\mathrm{m}^{2} / \mathrm{tree}\right)$ & 49.8 & 6.5 & 35 & 25.8 & 16.5 \\
Total leaf surface area $\left(\mathrm{m}^{2} / 100 \mathrm{~m}^{2}\right)$ & 598 & 385 & 524 & 516 & 478 \\
Biomass of leaves of one tree $(\mathrm{kg} / \mathrm{tree})$ & 10.5 & 1.2 & 7.1 & 5.0 & 3.4 \\
Total biomass of leaves $\left(\right.$ ton $\left./ 100 \mathrm{~m}^{2}\right)$ & 0.13 & 0.07 & 0.11 & 0.10 & 0.10 \\
Photosynthesis amount for unit area $\left(\mathrm{Kmol}^{2} \mathrm{y} \cdot 100 \mathrm{~m}^{2}\right)$ & 28.4 & 18.3 & 24.9 & 24.5 & 22.7 \\
Transpiration amount for unit area $\left(\mathrm{l} / \mathrm{y} \cdot 100 \mathrm{~m}^{2}\right)$ & 165 & 89 & 126 & 119 & 106 \\
\hline
\end{tabular}

all the stands. U1, U2 and U3 had a variety of stand density of 15-29 trees $/ 100 \mathrm{~m}^{2}$, but each tree height was in the narrow range of 8.3-8.6 $\mathrm{m}$, and so was the stand's age of between 18-20 years. In these stands, average crown length $(1.9-2.7 \mathrm{~m})$, crown width $(1.7-2.5 \mathrm{~m})$, diameter at breast height $(8.9-11.9 \mathrm{~cm})$, and crown length ratio (0.23-0.31), respectively, did not differ largely with each other but as the stand density became lower, the larger each value became. For the biomass of leaves, U1, U2 and U3 all had similar values $\left(0.10-0.11 \mathrm{t} / 100 \mathrm{~m}^{2}\right)$.

\section{Leaf surface area of each stand}

Leaf surface area of a 1-cm length of leaf was $0.23-0.25 \mathrm{~cm}^{2}$ in each stand. There was little difference between the stands. The length of the leaves was between 8-14 $\mathrm{cm}$ in each area.

In the $\mathrm{S} 1$ stand, the total leaf surface area of a tree was $49.8 \mathrm{~m}^{2}$. In $\mathrm{S} 2, \mathrm{U} 1$, U2, and U3 stands, those values were $6.5,35.0,25.8$ and $16.5 \mathrm{~m}^{2}$, respectively.

Biomass of leaves of a tree $(\mathrm{kg})$ in each stand was $10.5,1.2,7.1,5.0$, and 3.4, respectively for S1, S2, U1, U2 and U3 stands, respectively.

The leaf surface area of a unit forest area in each stand $\left(m^{2} / 100 m^{2}\right)$ was 598, 385, 524, 516, and 478 for S1, S2, U1, U2 and U3 stands, respectively. That value was the lowest in a highest density stand.

\section{Photosynthesis amount in each stand}

The relationship between the photosynthesis rate and PPFD is shown in Fig. 3. The plot points are the hourly values during 3 days for the respective season. In every season, as the PPFD increased, the photosynthesis rate increased. The photosynthesis rate was the highest in the summer of any PPFD, which was more than $2.5 \mu \mathrm{mol} \mathrm{m} \mathrm{m}^{-2} \mathrm{~s}^{-1}$. The second highest was the spring, followed by the autumn, and finally winter. In the winter, the photosynthesis rate was less than $0.5 \mu \mathrm{mol} \mathrm{m}^{-2} \mathrm{~S}^{-1}$ at any PPFD.

From these rates, the average photosynthesis amount during the day for a unit leaf surface area was calculated, and the annual total amount of photosynthesis for unit leaf surface area $\left(\mathrm{Kmol} / \mathrm{y} \cdot 100 \mathrm{~m}^{2}\right)$ was 28.4 for $\mathrm{S} 1 \mathrm{stand}$, 18.3, 24.9, 24.5 and 22.7 for S2, U1, U2 and U3 stands, respectively.

\section{Transpiration amount in each stand}

The sap flow velocity measured for example, for 3 days in February and August, respectively, was shown in Fig. 4. In August, the velocity increased rapidly after sunrise for each day and each stand, and fluctuated during the daytime between 30 and $100 \mathrm{~m} \mathrm{~s}^{-1} 10^{-6}$, and then decreased to less than $30 \mathrm{~m} \mathrm{~s}^{-1} 10^{-6}$ after $6 \mathrm{pm}$. The velocity was very small during the hours from sunset to sunrise.

In February, the velocity was small with less than $15 \mathrm{~m} \mathrm{~s}^{-1} 10^{-6}$ for every hour in each stand, showing a large difference between August and February.

Daily sap flow volume was 8 to $50 l d^{-1}$ for a year. There was little difference in it between the stands.

The annual average daily sap flow volume $\left(1 d^{-1}\right)$, or that of transpiration, was 37.6 for $\mathrm{S} 1$ stand, and 4.9, 22.9,

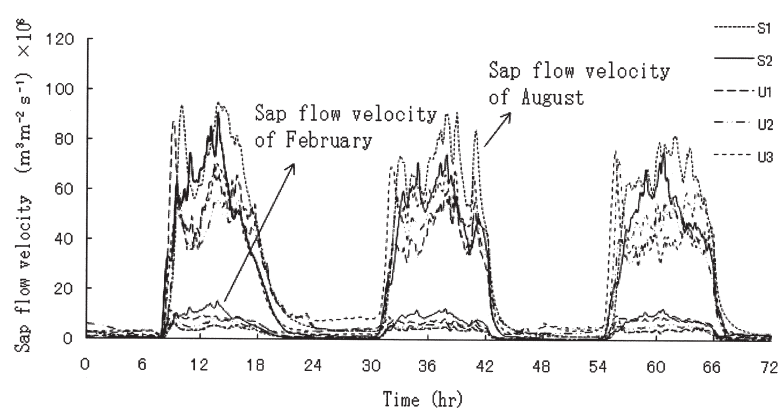

Fig. 4. Sap flow velocity of a tree in August and February. 
Table 2. Correlation between stand density, leaf surface area, biomass of leaves and amount of photosynthesis and transpiration

\begin{tabular}{|c|c|c|c|c|}
\hline & Stand density & Leaf surface area & Biomass of leaves & Photosynthesis amount \\
\hline Leaf surface area & $-0.95^{*}$ & & & \\
\hline Biomass of leaves & $-0.93^{*}$ & $0.99 * *$ & & \\
\hline Photosynthesis amount & $-0.95^{*}$ & $1.00 * *$ & $0.99 * *$ & \\
\hline Transpiration amount & -0.82 & $0.95 *$ & $0.95^{*}$ & $0.95 *$ \\
\hline
\end{tabular}

* : Significant at $5 \%$ level.

** : Significant at $1 \%$ level.

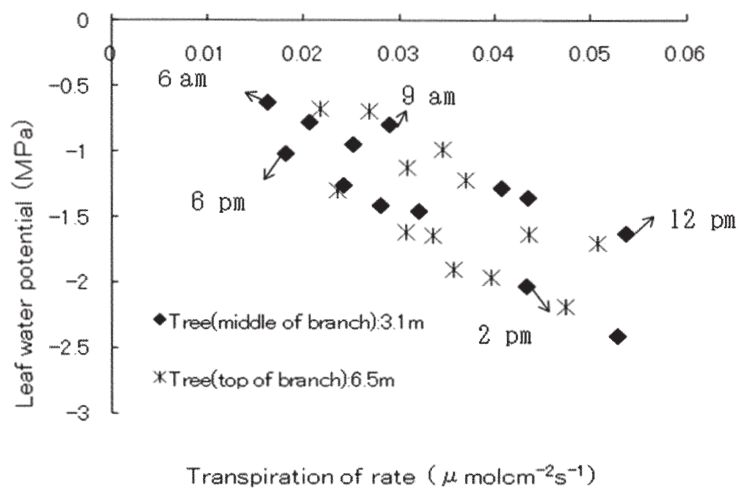

Fig. 5. Relationship between transpiration rate and leaf water potential for a branch.

17.9 and $11.6 l d^{-1}$ for S2, U1, U2 and U3 stands, respectively. Here, the sapwood area $\left(\mathrm{cm}^{2}\right)$ was $184,49,158$, 113 and 80 for S1, S2, U1, U2 and U3 stands, respectively (Table 1).

\section{Correlation between stand density, leaf surface area, biomass of leaves, and the amount of photo- synthesis and transpiration}

Table 2 shows the correlation coefficient between stand density, leaf surface area, biomass of leaves, and the amount of photosynthesis and transpiration calculated by using averages for each stand. Here, stand density negatively correlated with leaf surface area, biomass of leaves, and photosynthesis amount, respectively. On the other hand, leaf surface area positively correlated with biomass of leaves, and amount of photosynthesis and transpiration, respectively. Biomass of leaves correlated with the amount of photosynthesis and transpiration, and the photosynthesis amount correlated with the transpiration amount, respectively.

\section{Hydraulic resistance of the branch}

The relationship between transpiration rate and water potential for a leaf was shown in Fig. 5 for a branch $6.5 \mathrm{~m}$ long.

In the figure, plot means the hourly value for 3 days. At the middle of the branch, the transpiration rate ranged from 0.01 to $0.05 \mu \mathrm{mol} \mathrm{m}^{-2} \mathrm{~s}^{-1}$, and water potential from -2.2 to $-0.3 \mathrm{MPa}$. These values at the top of branch were almost the same with those in the middle of the branch. As the transpiration increased, the water potential decreased.
Table 3. Results of the t-test for the mean difference between middle and top of branch of a tree (A), and the oneway analysis of variance between 3 branches of different length (B), respectively

\begin{tabular}{cccc}
\hline $\begin{array}{c}\text { Analytical } \\
\text { method }\end{array}$ & $\begin{array}{c}\text { Combination of part/ } \\
\text { branch }\end{array}$ & Branch/part & p-value \\
\hline \multirow{2}{*}{ A } & $\begin{array}{c}\text { middle - top } \\
(\mathrm{n}=13)\end{array}$ & 1 & 0.26 \\
& branches 1-2-3 & 3 & 0.16 \\
B & $(\mathrm{n}=13)$ & middle & 0.21 \\
& top & 0.10 \\
\hline
\end{tabular}

Branches 1-3 were selected from the respective three trees on a forest stand, and have 6.5, 5.3 and $4.3 \mathrm{~m}$ long, respectively. $\mathrm{n}$ : number of observations.

After sunrise, both transpiration rate and water potential increased with time. Those values reach their maximum at between $12 \mathrm{pm}$ and $1 \mathrm{pm}$, after both values decreased with time. Water potential is higher in the morning by around $0.5 \mathrm{MPa}$ than in the afternoon for the same transpiration rate. Hourly changes in the transpiration rate and water potential for two other branches, which are not shown here, were similar as in this case.

If there is a difference in hydraulic resistance between the middle and top of a branch, the t-test for the mean difference analysis was performed for the branches. The results are shown in Table 3. According to Table 3, the p-value was not significant for all branches, and there was not a significant difference of hydraulic resistance between the middle and top of the branch.

Finally, one-way analysis of variance was performed for the resistance of the three branches to detect if there was a difference in the resistance according to the branch length. The results are shown in Table 3. From Table 3, there was no significant difference of the resistance between the branches at the middle and at the top of branch, respectively.

\section{DISCUSSION}

\section{Effect of photosynthesis on the growth of forest stand}

According to the correlation in Table 2, photosynthesis correlated with transpiration in amount, and also correlated with leaf surface area and biomass of leaves, 
respectively.

From the correlations, photosynthesis and transpiration were in proportion with leaf surface area and biomass of leaves. Here, the amount of photosynthesis and transpiration per unit leaf surface area and the amount per unit biomass of leaves were not different across the 5 forest stands.

The negative correlation between forest stand density and leaf surface area and the biomass of leaves for the unit stand area indicates that as the stand density becomes lower, the larger the stand growth of unit forest area became. Here, the photosynthesis contributed positively to the growth from the correlation between the photosynthesis amount and leaf surface area and biomass of leaves for the unit stand area.

Though the amount of transpiration correlated with photosynthesis, leaf surface area and biomass of leaves, it did not correlate directly with stand density (Table 2). For this reason, some factor(s) may have interfered with the relationship between transpiration and stand density, and therefore, further examination is necessary.

Here, if the thinning of trees on the stand is completed, stand density becomes lower and the growth of the stand is promoted through the action of photosynthesis.

\section{Effect of branch length on hydraulic resistance}

Though there was $2-3 m$ of distance between the top and middle of the branch, no significant difference in hydraulic resistance between the top and middle of the branch was observed (Table 3). It is considered that even at the top of the branch, the water necessary for transpiration is provided as plentifully as the middle of branch. As long as transpiration is not restricted, photosynthesis cannot be restricted and branch growth can be promoted. In the forest, as examined in the correlation, as the transpiration amount increased, which did not show any restriction, the photosynthesis amount increased as well.

Since there was no difference in the resistance between the branches, the lengths of which differed from each other (Table 3), transpiration could be expected to occur similarly between the branches as with photosynthesis. Growth ability did not differ with the length of the branch especially with long branches.

If thinning of forest trees is completed, the horizontal distance between the neighboring trees becomes larger and gaps between the tree crowns will appear; however, in this case, branches could grow further in length to reduce the gaps, which is true even if the thinning is performed extensively, considering the above characteristics. The growth of branch contributes to the increase in the biomass of leaves and leaf surface area of the trees.

\section{CONCLUSION}

The following conclusions were drawn from the present study.

(1) The forest stand density correlated negatively with leaf surface area, biomass of leaves and the amount of photosynthesis, respectively, for unit area of the black pine forest. The photosynthesis amount was proportional to the leaf surface area and biomass of leaves for the unit area.

(2) The transpiration amount positively correlated with photosynthesis amount, though the negative correlation was not observed between transpiration amount and the forest stand density.

(3) Hydraulic resistance, expressed by the ratio of water potential to transpiration rate of a branch, was not different between the top and middle of branch, showing that growth ability at the top of branch was maintained as well as that in the middle of the branch. There was no difference in the resistance between branches, when the lengths were different.

(4) If stand density was lowered by thinning forest trees, even extensively, growth of forest stand was promoted through the increase in photosynthesis. Further growth in branches is expected even for a long branch, which will contribute to the forest stand growth.

\section{REFERENCES}

Holbrook, N. M. and Lund, C. P. 1995 Photosynthesis in Forest Canopies. "Forest Canopies"ed. byLowman, M, D. and Nadkarni, N. M. Academic Press, pp. 411-430

Japan Meteorological Agency 2009 Weather statistics information. Available from <http://www.data.jma.go.jp/obd/stats/ etrn/>

Kaneko, T. and Tamura H. 2002 Study about the technology the fitness of the coastal pine tree. Akita prefecture forest technology center duties annual report., 14: 11-12

Kikuzawa, K. \& Lechosicz, M. J. 2006 Towards a synthesis of relationships among leaf longevity, instantaneous photosynthetic rate, lifetime leaf carbon gain and the gross primary production of forest. American Naturalist., 168: 373-383

Koike, T. 2004 Tree ecology Asakura publication, pp. 89-93

Kosugi, Y. Shibata, S. Matsui, K. and Kobashi, S. 1997 Differences between deciduous and evergreen broad-leaved trees in the pattern of seasonal change of leaf-scale photosynthetic net assimilation rate and transpiration rate. $J$. Jap. Soc. Reveget. Tech., 22(4): 205-245

Kumagai, T. 2001 Modeling water transportation and storage in sapwood -model development and validation. Agricultural and Forest Meteorology., 109-2: 105-115

Osada, N. Tateno, R. Hyodo, F. and Takeda, H. 2004 Changes in crown architecture with tree height in two deciduous tree species: developmental constraints or plastic response to the competition for light? Forest Ecology and Management., 188: $337-347$

Nagasuga, K. and Kubota, F. 2006 Change hydraulic resistance and shoot morphology of napiergrass (Pennisetum purpureum schumach) under shaded condition. Plant Prod. Sci., 9(4): 364-368

Zots, G. and Winter K. 1994 Photosynthesis of a tropical canopy tree, Ceiba pentandra, in a lowland forest in Panama. Tree Physiology., 14: 1291-1301

Zots, G., Harris, G., Koniger, M. and Winter K. 1995 High rate of Photosynthesis in the tropical pioneer tree, Ficus insipida Willd. Flora., 190: 265-272

Zots, G. and Winter, K. 1996 Diel patterns of $\mathrm{CO}_{2}$ exchange in rainforest canopy plants. "Tropical Forest Plant Ecophysiology" (ed. By Mulkey, S. S., Chazdon, R. L. and Smith, A. P.) Chapman and Hall, NY, pp. 89-113 